\title{
Examining Gaps between Students' Expectations and Experiences in a Private University
}

\author{
Mohd Mahzan Awang ${ }^{1}$ \\ Abdul Razaq Ahmad 1 \\ Nora'asikin Abu Bakar² \\ Sayuti Abd Ghani ${ }^{3}$ \\ Che Pee Saad 4 \\ Saliza Husin ${ }^{2}$ \\ Zaharuddin Hashim² \\ Mohd Asrul Hery lbrahim²

\begin{abstract}
Alfitri ${ }^{5}$
Universiti Kebangsaan Malaysia', Infrastructure University Kuala Lumpur2, National Defence University of Malaysia ${ }^{3}$, University Islam Malaysia Council4, University of Sriwijaya ${ }^{5}$

Email:mohdmahzan@gmail.com
\end{abstract}

Doi:10.5901/mjss.2014.v5n8p396

Abstract

This study examined students' expectations and experiences of academic and social life in a private university. This study employed a survey research design in which a set of fixed-response and open-ended questionnaire has been used. The questionnaire contains five main areas, namely (1) conducive campus facilities and learning environment; (2) good support services; (3) attractive co-curricular activities; (4) positive socio-relationship with university staff and lecturers; and (5) sociorelationship with local community. A total number of 540 university students were randomly selected to participate in this study. Numeric data collected was analysed using descriptive and inferential statistics. Narrative data collected was used to expand the views regarding the areas explored. Results indicated that there is a significant difference between students' expectations and their experiences with regards to the academic qualities and social life. Results in this study revealed that most of the students' expectations were not met. This is alarming for the survival of private universities as it would affect the university's reputation and students' unwillingness to recommend for others. This study also found that improvement on campus facilities and socio-interaction with university staff are the most important aspects for students. Therefore, a prompt action to improve and upgrade those aspects is vital. This paper recommends a specific action to overcome gaps between expectations and experiences by using a holistic approach.

Keywords: expectations; experiences; gaps; social life; student's satisfaction; private university

\section{Introduction}

Students are the most important stakeholders for the survival and development of private universities. Without constant student enrolment, private universities may have difficulties to survive or improve their services. As private higher institutions are dependent on student enrolment, students' satisfaction and their ability to complete their studies are essential. However, in Malaysian context, far too little attention has been paid to explore students' experiences in private higher education institution compared to those in public universities. This may be due to a strict policy in most private higher education institutions. The most relevant research in this area was conducted by Baharuddin (2003) who investigated the students' expectations and perception on services provided by private colleges in Malacca. The study revealed that most students have high expectations towards those colleges. However, the study did not explore students' social life in private higher education, which is one of the areas to be researched in this proposed study. In addition, most studies in the past, particularly in Malaysian context, tended to focus on academic achievement rather than their 
experiences at the university. As a result, there is unclear evidence to comprehend students' experiences in higher education institution.

Students have many choices for their tertiary education as there are 469 private higher education institutions in Malaysia that offer various academic programmes from certificate to doctoral levels. Thus, the institutions need to be more proactive by offering attractive schemes to be more competitive and popular among prospective students. These institutions were observed to advertise the positive aspects of their institutions in various ways. Some of them highlight their strengths in infrastructure and facilities, accredited academic programmes and quality services. However, students' perceptions towards these elements are unclear. Indeed, it is unknown to what extent students' expectations towards those matters are met. Our general observation revealed that more international students were not satisfied with the services provided and felt unhappy with the academic and social life environment. As a result, this has negatively affected the university reputation and poorly impacted on students' well-being. It should be noted that students' recommendation has been found to be a powerful marketing strategy. Empirical research shows that most students recommended certain universities for two reasons: the universities' reputation, and their experiences while studying in those universities (Mazzarol \& Soutar, 2002). As students have first-hand experiences on academic programmes and social-life, their participation in this research is vital. A lot of studies in the past, particularly in a Malaysian context, have tended to focus on academic achievement rather than students' experiences. As a result, there is insufficient evidence to support views on students' experiences in higher education institution.

\section{Academic and Social Life in University}

Extensive past studies highlighted the importance of conducive learning ecology for improving students' satisfaction in campus life and their academic performance. For instance, a study carried out by Tessema, Ready and You (2012) revealed that students' satisfaction and happiness in both campus life and academic life have a significant relationship with five factors namely quality of instruction, capstone experience, academic advising, overall college experience and preparation for career. These five factors describes students' life and its effects on their feelings towards support system provided by the educational institution. Detailed analysis of their study revealed that gender plays an important variable determining the satisfaction level. The study found that students' satisfaction level differs by gender where female tended to feel more supportive than male (Tessema, Ready and You, 2012). Indeed, many empirical studies revealed that there are differences in expectations between genders towards educational support system (Delaney, Harmond \& Redmond, 2010) which has influenced their satisfactory level (Umbach and Porter, 2002). Dee (2006) has analysed and critically discussed the influence of genders affecting student-teacher interaction and students' engagement in the lesson. Empirical research carried out by Umbach and Porter (2002) on university alumni $(n=1300)$ revealed that students' satisfaction in academic and social life is dependent on the quality of social interaction between peers and university staff.

As students are capable to decide and choose the tertiary education institution they want to apply for admission, a clear understanding of the influencing factors is essentials. In addition, the liberalization of higher educational institutions around the world has given great opportunities for students to choose for themselves the universities and areas of studies. Therefore, university reputation and peer recommendation is important. Word-of-mouth marketing (also known as WOM marketing) via information communication technology is a powerful engine for building reputation. Dissatisfaction among students will open a huge platform for damaging a university's reputation. To understand this situation, Bronfenbrenner's Ecological System Theory (1994) may be able to provide a clear picture. The theory considers the entire ecological system of an individual, in which growth occurs, as the pillar for human behaviour. This system theory is divided into five subsystems, namely: microsystem, masosystem, exosystem, macrosystem and chronosystem which are interconnected with each other. The current study focuses on chronosystem which deals with students' expectations before enrolling to the university, and the experiences that they gained after studying at the universities. It examines students' expectations and experiences of academic and social life. Narrative data collected would be used to explain about their experiences in academic and social life.

\section{Research Methodology}

The survey research design was employed in this study. Instruments used in this study was a set of fixed-response and open-ended questionnaire. The questionnaire contains five aspects including campus facilities and learning environment, student support services, co-curricular activities, relationship with university staff and lecturers, and relationship with outside community. A five-point Likert scale was used in the questionnaires to allow the students to express their level of satisfaction, where the score of 1 indicates the highest level of satisfaction, whereas 5 the highest level of dissatisfaction. 
In order to validate the instrument, a pilot test was carried out in one of the universities in Malaysia. The Cronbach's alpha values for all items were more than 0.80 which informs that the items are acceptable. The actual data collection was held in one of the private universities in Malaysia. This university was chosen due to enrolment fluctuations in the number of students' intake which may have an impact on its reputation. In addition, this university has just been upgraded to a fullfledged university after the Malaysian government satisfied with the quality of graduates produced. A total number of 540 university students participated in this study. They were randomly selected by considering their willingness to participate in this study. Numeric data collected was analysed by using SPSS, whereas narrative data collected was analysed manually. Narrative data was used to expand the students' views on academic and social life.

\section{Findings and Discussion}

The majority of respondents participated in this study were Muslim $(n=329)$, followed by Buddhist $(n=72)$, Hindu $(n=71)$, and Christians ( $n=41$ ). A number of 386 males and 154 females participated in this study. 417 were Malaysians and 123 were foreign students. 350 were bachelor's degree students and 190 were diploma students. 171 lived in hostel, whereas 369 lived outside. Overall results demonstrated that half of the students in this study reported that they were happy studying at the university. They reported that most academic programmes offered by this university are relevant for the job market and most courses were taught by expert lecturers. In terms of social life at this university, nearly half of students (47\%) reported that they were happy and enjoy with the campus ethos.

The current study found that there is a big gap between students' expectations and experiences in six areas investigated namely: campus facilities and learning environment (mean difference $=0.987$ ); student support services (mean difference $=0.742$ ); co-curricular activities (mean difference $=0.682$ ); relationship with local community (mean difference $=0.659$ ); and relationship with university staff and lecturers (mean difference $=0.500$ ).

\subsection{Campus facilities and learning environment}

Overall results show that there are significant differences between expectation and experience among respondents with regards to seven areas. Table 1 shows that most respondents had a higher expectation than what they experienced. This means that their expectations towards learning environment, relaxing spaces, hostel condition, campus life, laundry services, campus, and appreciation of culture are not being fulfilled. As private universities are more likely to depend on the students' enrolment, dissatisfaction towards these aspects may affect the university's image and reputation. The importance of students' satisfaction has been highlighted by authors of several past studies such as Shadrack (2013) and Tam (2011). Based on these findings, strategic actions to upgrade facilities and promote positive learning environment are really needed.

Detailed investigation on each component within campus facilities and learning environment revealed that students expected the campus to be conducive for learning, have sufficient space for relaxing, good hostel conditions and superior laundry services. However, students reported that their expectations were not met. Most students reported that they were not satisfied with most of the facilities at this university. Most students stated the biggest gap in their expectations about the hostel condition as they felt dissatisfaction with the hostel condition. This is something important to be explored in future research as past empirical research revealed that the occurrences of many critical issues and incidents in the hostel are the contributing factors to students' dissatisfaction. These include bullying and social discrimination. It has been reported in the past that there is a tendency of bully behaviour in hostel and outside the educational institution (Tjavanga \& Jotia, 2012; Kuntsche, Knibbe, Engels \& Gmel, 2007). It might be linked with negative behaviour such as drinking habit and substance use.

Table 1. Students' expectations and experiences of seven main constructs

\begin{tabular}{|c|c|c|c|c|c|c|c|}
\hline Constructs & $n$ & $\begin{array}{r}\text { Mean } \\
\text { Expectation }\end{array}$ & $\begin{array}{l}\text { Score } \\
\text { Experience }\end{array}$ & Mean Difference & Standard deviation & $t$ & Sig.* \\
\hline Conducive learning environment & 540 & 3.931 & 3.169 & 0.763 & 1.212 & 14.629 & 0.000 \\
\hline Space for relaxing & 540 & 3.846 & 2.781 & 1.065 & 1.426 & 17.347 & 0.000 \\
\hline Hostel conditions & 540 & 3.659 & 2.267 & 1.393 & 1.568 & 20.642 & 0.000 \\
\hline Laundry service & 540 & 3.615 & 2.463 & 1.152 & 1.462 & 18.312 & 0.000 \\
\hline Enjoyable campus & 540 & 3.843 & 2.943 & 0.900 & 1.430 & 14.623 & 0.000 \\
\hline Culture of appreciation & 540 & 3.835 & 3.190 & 0.648 & 1.222 & 12.323 & 0.000 \\
\hline Average means score & 3240 & 3.789 & 2.802 & 0.987 & 1.414 & 39.732 & 0.000 \\
\hline
\end{tabular}


Narrative data collected revealed that campus facilities and physical maintenance are the common issues raised by most students in this study. Expanding their feeling towards physical environment and campus facilities of this university, some students said that:

"I am not satisfied with the facilities.... Toilets are dirty" (Student 242, male, Malay, Bachelor's degree, aged 21)

One student highlighted his dissatisfactions towards the cleanliness of cafeteria and student hostel.

"Cleanliness of the cafeteria is totally bad" (Student 221, male, Indian, Bachelor's degree, aged 22)

"...the hostel is not clean ..." (Student 42, female, Indian, Bachelor's degree, aged 23)

The same student also raised issues of internet, parking lots and facilities for pedestrians.

"...the Wifi are slow, too much speed bump and less parking lot ... there is no covered-walkways to certain place, so when it rains it troubles for us" (Student 42, female, Indian, Bachelor's degree, aged 23)

Due to poor internet networking services, many students have a problem to get the latest information and references. He mentioned that the library books are outdated. One student reported that:

\begin{abstract}
"The Internet surround the campus is very slow; sometimes we cannot connect it also ... books at the library is outdated as well" (Student 27, male, Chinese, Bachelor's degree, aged 22)
\end{abstract}

This leads to dissatisfaction among students.

"I dislike the environment (especially) classroom, lab and library" (Student 216, female, Malay, Bachelor's degree, aged 22)

"I am not sure about my feeling towards this university, but you can imagine where there is a lot of problems in terms of space for relaxing, cafe, discussion room and lab ..." (Student 42, female, Indian, Bachelor's degree, aged 23)

\title{
4.2 Student support services
}

Overall results indicate that there is a significant difference between the university students' expectations and their experiences with regards to three components of student support service. A big gap is found with regards to sports equipment based on the data obtained from most students that the university has insufficient sports equipments.

Table 2. Students' expectations and experiences of student support services

\begin{tabular}{|c|c|c|c|c|c|c|c|}
\hline Aspects & $\mathrm{n}$ & $\begin{array}{r}\text { Mean } \\
\text { Expectation }\end{array}$ & $\begin{array}{l}\text { Score } \\
\text { Experience }\end{array}$ & Mean Difference & Standard deviation & $\mathrm{t}$ & Sig.* \\
\hline Sports equipment & 540 & 3.669 & 2.535 & 1.134 & 1.455 & 18.106 & 0.000 \\
\hline Student involvement in sports activities & 540 & 3.752 & 2.844 & 0.908 & 1.390 & 15.170 & 0.000 \\
\hline Support staff to solve social issues & 540 & 3.761 & 2.837 & 0.924 & 1.430 & 15.019 & 0.000 \\
\hline Average means score & 540 & 3.727 & 2.739 & 0.742 & 1.428 & 27.858 & 0.000 \\
\hline
\end{tabular}

Although statistical data (Table 2) shows some discrepencies between expectations and experiences of students, there is insufficient narrative data to expand those differences. In-depth study to understand this matter is suggested to be explored in future research.

\subsection{Co-curricular activities}

Results from this study revealed that there are significant differences between students' expectations and their experiences with regard to co-curricular activities components. Many students expected that sports activities organised at the university are all attractive. However, their expectations were not met. The result showed the same for other components. There is insufficient narrative data to expand the students' views on co-curricular activities at the university (Table 3). 
Table 3. Students' expectations and experiences of co-curricular activities

\begin{tabular}{|lccccccc|}
\hline \multicolumn{1}{|c}{ Aspect } & $\mathrm{n}$ & Expectation & Experience & Mean Difference & Standard deviation & $\mathrm{t}$ & Sig. ${ }^{*}$ \\
\hline Attractive sports activities & 540 & 3.713 & 2.655 & 1.058 & 1.489 & 16.523 & 0.000 \\
Proactive SRC & 540 & 3.739 & 3.120 & 0.619 & 1.309 & 10.981 & 0.000 \\
Participation in various extracurricular activities & 540 & 3.702 & 2.983 & 0.719 & 1.356 & 12.3120 .000 \\
Many socio-religious activities & 540 & 3.724 & 3.124 & 0.600 & 1.272 & 10.964 & 0.000 \\
Cultural activities & 540 & 3.819 & 3.404 & 0.415 & 1.276 & 7.557 & 0.000 \\
Average means score & 540 & 3.739 & 3.057 & 0.682 & 1.358 & 26.090 & 0.000 \\
\hline
\end{tabular}

\subsection{Co-curricular activities}

Table 4 shows that the students' expectations were higher than their experiences. This means that their expectations were not fully met. The highest mean score for students' expectations is on the item "supportive lecturers". The students hoped that their lecturers could support and help them in their studies.

Table 4. Students' expectations and experiences of the interaction with staff and lecturers

\begin{tabular}{|lccccccc|}
\hline \multicolumn{1}{|c}{ Aspect } & $\mathrm{n}$ & Expectation & Experience & Mean Difference & Standard deviation & $\mathrm{t}$ & Sig. $^{*}$ \\
\hline Friendly admin staff & 540 & 3.796 & 3.006 & 0.113 & 1.420 & 12.937 & 0.000 \\
Supportive admin staff & 540 & 3.785 & 2.931 & 0.854 & 1.413 & 14.044 & 0.000 \\
Helpful admin staff & 540 & 3.793 & 3.028 & 0.765 & 1.364 & 13.045 & 0.000 \\
Friendly lecturers & 540 & 3.959 & 3.563 & 0.396 & 1.249 & 7.372 & 0.000 \\
Supportive lecturers & 540 & 3.956 & 3.498 & 0.458 & 1.203 & 8.836 & 0.000 \\
Helpful lecturers & 540 & 4.011 & 3.624 & 0.387 & 1.127 & 7.983 & 0.000 \\
Expert lecturers & 540 & 3.994 & 3.465 & 0.529 & 1.124 & 10.953 & 0.000 \\
Average means score & 540 & 3.899 & 3.302 & 0.597 & 1.289 & 28.479 & 0.000 \\
\hline
\end{tabular}

Students also expected that the university staffs were friendly and supportive. Expanding their views on this matter, some students reported that they had problems with some administrative staff. For instance, one student said that:

"Staff at one of the administration section is arrogant" (Student 242, male, Malay, Bachelor's degree, aged 21)

Another student reported that some staff members were rude.

"Some staffs from one department are rude to students" (Student 23, female, Indian, Foundation course, aged 18)

One student asserted that some lecturers were racist.

"The lecturers are racist and careless" (Student 7, male, Libyan, Bachelor's degree, aged 23)

A lack of socio-interaction opportunities across genders and cultures are found to be an issue for some students at this university. One student stated that:

"I am not satisfied here because there are no social connection between genders and culture" (Student 242, male,

Malay, Bachelor's degree, aged 21)

Many students involved in this study expected that they would gain much experience by interacting with lecturers, international students and people from different ethnicity.

"It was a good experience to see the new culture here" (Student 4, male, Malay, Bachelor's degree, aged 24)

"The life in this university is good especially when you have friendly lecturers and friendly friends" (Student 25, male,

Iraqi, Bachelor's degree, aged 24) 


\subsection{Relationship with the local community}

Table 5 shows that the average mean score for students' expectations were higher than their experiences, indicating that the students' expectations were not met.

Table 5. Students' expectations and experiences of their relationship with local community

\begin{tabular}{|lccccccc|}
\hline \multicolumn{1}{|c}{ Aspect } & $\mathrm{n}$ & Expectation & Experience & Gap & Standard deviation & t & Sig. $^{*}$ \\
\hline Involvement in community services & 540 & 3.789 & 3.135 & 0.654 & 1.208 & 12.577 & 0.000 \\
Suitable community service & 540 & 3.802 & 3.139 & 0.663 & 1.244 & 12.380 & 0.000 \\
Effective inter-agency partnership & 540 & 3.824 & 3.165 & 0.659 & 1.251 & 12.248 & 0.000 \\
Average means score & 540 & 3.805 & 3.146 & 0.659 & 1.234 & 21.488 & 0.000 \\
\hline
\end{tabular}

However, there is insufficient narrative data to expand the students' views on their relationship with local community.

\section{Conclusion}

Overall, the current study found that students' expectations were not fully met. The biggest gap exists in terms of Campus Facilities and Learning Environment and Student Support Services. This might affect student's enrolment to the university. Due to this situation, students may choose to live outside campus which may possibly affect their commitment to academic and co-curricular activities. It would be more possible negative implication when the students' expectations were not met. In order to minimise those gaps, improvement of the hostel management is vital. As students are the most important stakeholders for the university survival, their voice should be heard. In fact, their feedback should be treated in a very positive manner. follows:

The key recommendations to bridge the gap between students' expectations and their actual experiences are as

- appointing qualified and well experienced personnel in the relevant areas and fields,

- increasing budget and recognising the need to put more emphasis on co-curricular and sports activities,

- providing adequate training to staff and personnel who are required to handle and provide student support and counselling services, and

- making the university staff realise that the university is responsible for producing well-rounded, qualified and healthy individuals who have close relationship with the community

\section{References}

Bronfenbrenner, Urie. (1994). Ecological Models of Human Development. International Encyclopaedia of Education. 3(2). Oxford.

Tessema, M.T., Ready, K. and You, W-C.W. (2012). Factors Affecting College Students' Satisfaction with Major Curriculum: Evidence from Nine Years of Data. International Journal of Humanities and Social Science. 2(2), 34-44

Dee, T.S. (2006). Teachers and the Gender Gaps in Student Achievement. The Journal of Human Resource. XLII (3), 528-554

Delaney, L., Harmon, C. \& Redmond, C. (2010). Decomposing Gender Differences in College Student Earnings Expectations. UCD Geary Institute Discussion Paper Series. 1-40

Kuntsche, E., Knibbe, R., Engels, R. \& Gmel, G. 2007. Bullying and fighting among adolescents - Do drinking motives and alcohol use matter? Addictive Behaviors. 32, 3131-3135

Umbach, P.D. \& Porter, S.R. (2002). How Do Academic Departments Impact Student Satisfaction? Understanding the Contextual Effects of Departments. Research in Higher Education. 43(2), 209-234

Sahin, I. (2007). Predicting Student Satisfaction in Distance Education and Learning Environments. Turkish Online Journal of Distance Education. 8(2), 113-119

Shadreck, M. 2013. School Based factors and the Dropout Phenomenon: A Study of Zhomba Cluster Secondary Schools in Gokwe District of Zimbabwe. Journal of Educational and Social Research. 3(1), 51-60

Tam, W. 2011. Hidden School Disengagement and Its Relationship to Youth Risk Behaviors in Hong Kong. Educational Research Journal. 26(2), 175-197

Tjavanga, H. \& Jotia, A.L., 2012. School Bullies and Education in Botswana: Impact on Other Students and Academic Performance. 2(1), 641-650. 